\title{
Erratum to: Plastid biotechnology for crop production: present status and future perspectives
}

\author{
Jihong Liu Clarke $\cdot$ Henry Daniell
}

Published online: 27 July 2011

(C) Springer Science+Business Media B.V. 2011

\section{Erratum to: Plant Mol Biol (2011) 76:211-220 \\ DOI 10.1007/s11103-011-9767-z}

Due to an unfortunate misunderstanding, part of the Acknowledgments section was omitted in the original publication causing a funding agency not to be properly acknowledged. The correct information is published below and should be treated as definitive by the reader.

\begin{abstract}
Acknowledgments We thank the Research Council of Norway for grant BILAT-174998/D15, the GLOBVAC program for grant NFR192510/S50 (JLC), as well as Bioforsk core funding to Jihong Liu Clarke and USDA-CSREES, USDA-NIFA and NIH 2 R01 GM 063879 to Henry Daniell. The authors thank Nicholas Clarke and Sonja Klemsdal for critical reading and Shuai Guo for his help with references.
\end{abstract}

The online version of the original article can be found under doi:10.1007/s11103-011-9767-z.

\section{J. L. Clarke $(\bowtie)$}

Plant Health and Protection Division, Bioforsk- Norwegian Institute for Agricultural and Environmental Research, Hoegskoleveien 7, 1432 Aas, Norway e-mail: jihong.liu-clarke@bioforsk.no

\section{H. Daniell}

Department of Molecular Biology and Microbiology, College of Medicine, University of Central Florida, 336 Biomolecular Science Building, Orlando, FL 32816-2364, USA

e-mail: daniell@mail.ucf.edu 